\title{
Method Research to Improve Inventory Management based on Enterprise Resource Planning(ERP) Environment
}

\author{
Lingling $\mathrm{Yi}^{1,}$, , Jianfei $\mathrm{Tu}^{1, \mathrm{~b}}$ \\ ${ }^{1}$ School of Ningbo University, Zhejiang 315211, China; \\ a1476350421@qq.com, btujianfei@nbu.edu.cn
}

Keywords: ERP, Inventory management, business process, material, information flow, improving method.

\begin{abstract}
For manufacturing enterprises, effective inventory management strategies can speed up the funds flow and reduce some unnecessary cost. In this paper, by researching the current inventory management status of an energy company and on the basics of widely reading the literature about inventory management at home and abroad, finding that the disordered material management becomes a common problem in manufacturing enterprise. By researching the root of the problem to some extent and on the basis of the original inventory management methods, putting forward a number of improvements and some reasonable inventory management method: For materials management problem based on ERP, optimizing the business processes, tracing and coding the material can achieve the optimal allocation of resources.
\end{abstract}

\section{Introduction}

Today, enterprise informatization has become a major strategy on business development, which is one of the most effective way to improve the enterprise management level ${ }^{[1]}$. In this background, ERP system is widely used in the company, especially in manufacturing enterprises. Inventory management is an indispensable part of business activities and it is the effective measures to realize the materials planning, coordination and control. It's also a key factor to ensure the continuous improvement of enterprise productivity and achieve cost-controlling. In order to realize modern inventory management, it must optimize some business processes. So, in the ERP environment, what should companies do to manage the inventory more effectively?

This paper used company $\mathrm{S}$ as the background. Based on some issues present in the inventory management, this study puts forward some methods that using ERP system's business management and inventory management of supply chain to solve these problems. Combined with characteristics of ERP and inventory management, the study analyzes the reasons that cause inventory problems from multiple angles, namely, the company's management, supply chain operations and information flow. It presents some guide policies that optimize business processes, ensure fast and accurate transfer of materials and information flows and strengthen the material set-management.

This paper focus on discovering the disordered material management problem that widely exist in manufacturing enterprise and putting forward some material management methods to solve the problem combined with the condition of a energy company's inventory management and my own work experience and based on a widely reading of inventory management literature at home and abroad. Supply chain management is inseparable from the information management, it is necessary to use ERP to achieve the most optimal allocation of corporate resources. The results can be an useful supplement for inventory management theory in the information age, which in turn improve inventory management further.

\section{Literature Review}

The Content of Inventory Management. The content of inventory management is widely. It is necessary to deal with the various departments and staff, but also to deal with thousands of materials. Zhou Taiping.etc ${ }^{[2]}$ thought that all management methods referencing materials and economic-related 
are the areas of inventory management.Inventory management tools must be a combination of economic and technical, but the final result must be economical.

Inventory management content can make the distinction between hardware and software: Hardware construction and management, and the software system's building. The hardware facilities management includes the selection of warehouse site, the planning of storage area, the selection and use of storage facilities, etc ${ }^{[3]}$. While the software including the introduction and use of the information system, and the method to inventory management. Construction of information management system is not only operating computer, but embodying the warehouse management ideas and methods in the system.

From the narrow aspect, the inventory management content is related to material management activities $^{[4]}$. It's from materials' procurement, storage and recipient management, among which the most critical and tedious work is the storage, because it requires accounted.

Material Flow and Information Flow of Inventory Management. The material flow in inventory management, namely the flowing direction of material. Under normal circumstances, there are several main warehouse: raw materials warehouse, semi-finished products warehouse, finished products warehouse and transferring warehouse of workshop, and so on. Material flow from the raw materials warehouse to the transferring warehouse of workshop, arriving at finished products warehouse at last. If there is some waste during the process, putting it in the waste warehouse. Whatever the warehouse, the flowing form of materials is the same, namely input and output.

The information flow in inventory management is a form of material flow and corresponding material existing in ERP system. All the flows of document and the changes of data can be called information flow. The information flow of a certain raw material from purchase receipt to be processed and to be sold at last in the ERP system is :Purchase Order-Purchase Receipt-Production Picking List-Product Receipt List - Sales of Outbound Order. In this process, in order to facilitate trace, all forms of materials should have an uniform number, batch management approach is used in the study. The flowchart of material flow and information flow in the inventory management are shown in Figure1.

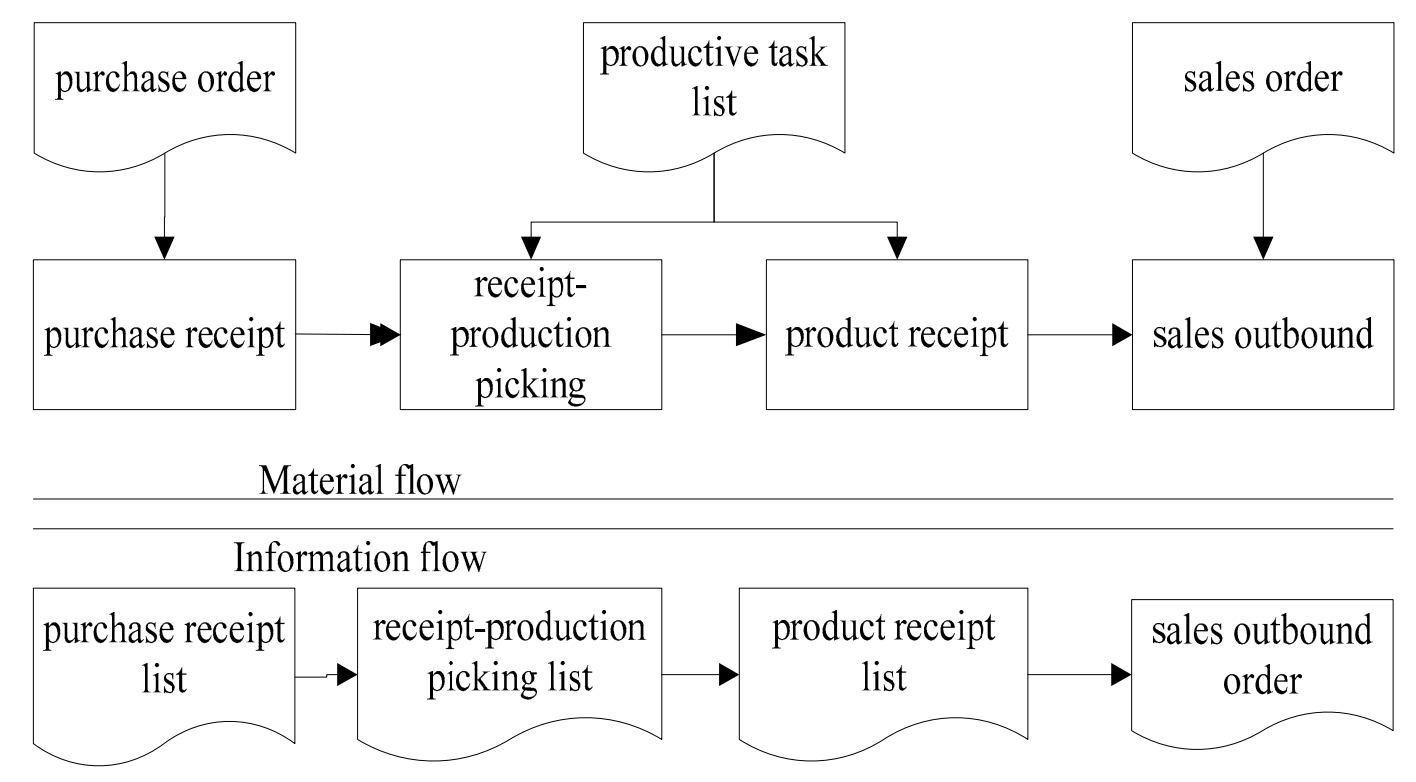

Fig.1 material flow and information flow in the inventory management

The concept of ERP. ERP, the abbreviation of Enterprise Resource Planning, was proposed by GartnerGroup. InC consultants and research institutes in the early 1990s. It refers to use the system thoughts to provide a management platform of decision-making and enterprise-running for managers and staff based on the building of information system ${ }^{[5]}$. Now ERP is not just a computer management software, but an information management system. people, financial, material, corresponding material 
flow and information flow and capital flow, etc.can be tightly integrated together in the system, so that enterprises' resources can be rational allocated ${ }^{[6]}$.

The core management ideas of ERP are mainly reflected in the following aspects:

1) It can help the enterprise to realize management innovation ${ }^{[7]}$. The enterprises usually reform in the way to management after implementing ERP, including mobility business processes, departments, and many other settings. The reform is not just a change of a job content and a personal manner,but a change of the previous old thoughts, re-injecting new ideas.

2) Manage the enterprise from the perspective of the system. ERP system is composed of the entire supply chain, production management, project management, financial accounting and other functional modules. It does not only concern about the enterprises' unilateral warehouse management or sales management ${ }^{[9]}$. It is an integrated system that can realize the product's life-cycle management, but also to achieve to control the finance and cost.

\section{Case Study}

The Company Background. Company $\mathrm{S}$ is a middle and small-sized enterprise that product and sell polysilicon ingots and polysilicon sheets. There are a total of three workshop in the company: cleaning shop, stove shop and prescribing workshop. Among witch the prescribing workshop has three procedures:prescribing, getting rid of head and tail, grinding. There are three main warehouse: raw material warehouse, semi-finished products warehouse and finished products warehouse. All raw materials must be clean and then they can get into the stove workshop to forge and form a ingot. An aluminum ingot is usually about $500 \mathrm{KG}$. Then the aluminum ingot form 25 polysilicon ingots after prescribing, getting rid of head and tail and grinding. The silicon block will be subcontract out to get the final product polysilicon sheets.

This company is rather special, because the recipe of each ingot is different and therefore it can't make the bill of material(BOM), production order and material requirements planning(MRP). Companies only can arrange procurement and production based on actual orders. Production processes in the system can not be well controlled. Fortunately, the production processes are not very complicated and we can control the production processes through materials storage and transceiver.

The Condition of Inventory Management. There are three main warehouse: raw material warehouse, semi-finished products warehouse and finished products warehouse. All the ingots and silicon blocks are placed in semi-finished products warehouse and silicons are placed in the finished product warehouse. Using the methods to historical data analysis and questionnaire finds many issues in the inventory management of company S:

1) All materials' sending and receiving are relied on recording by hand and then make spreadsheet to calculate the number and amount. Consequences waste a lot of manpower, however,we can not get satisfactory results. Accounting by hand is not only cumbersome and error-prone, but also the differences between accounts and the situation reality are inevitable.

2) The disordered material management. Objective reasons for the disordered material management are that there are thousands of materials involving manufacturing production activities. It is not easy to manage that if all the materials are not coded and regardless of the batch, even don't follow the process of operation. Subjective reasons are that the managers' improper management and they don't use the advanced management techniques and device to manage warehouse, what's more, inventory management philosophy is too traditional

The specific manifestations of chaos material management in inventory management.

(1) Materials are placed at random and not categorized, it's inconvenience to staff;

(2) Materials are not partitioned;

(3) Inventory is not accurate, and it is just a formality;

(4) Receipting and picking are random and it usually waste a large amount of time;

(5) Waste materials are not handled in time and occupy a large space.

3) Too many waste materials are difficult to classify. Since each process will produce some return charges and waste, and these waste materials can be recycled to raw material warehouse, avoiding 
wasting. Therefore, managers need to figure out the waste is generated from which aluminum ingot, then it's easy to sort out the waste materials.

Project Objective. The implementation of ERP is to achieve two goals: firstly, to make the material management more standardized. Secondly, to make the whole enterprise's material flow and information flow more smoothly to facilitate the managers to keep abreast of company dynamic and control all aspects of the enterprise. Using ERP warehouse management system can make the material management and warehouse management easy to operate, but also facilitate managers have a real-time view and regulator.

\section{Improving Methods}

For the materials management problems that have been raised previously, the text proposes several solutions. To solve the material management chaos problem, three aspects must be done. Firstly, the material must be encoded. The code just like material ID number, only the coded material can enter the relevant information in ERP system. Secondly, it can carry out batch management. We can track the defective products are produced by which materials, and then to solve the root of the problem; Finally, optimize the flow of materials transceiver and make the management more standardized throughout the whole warehouse.

Material Coding. Material coding can help improve the accuracy of the procurement, storage, requisition of materials and other operations, to reduce information distortion in the transmission process. Materials encoding can use the format of warehouse code + materials category code + water code. Raw material warehouse code is 01 , semi-finished products warehouse code is 02 , finished products warehouse code is 03 and the material category code starting at 01 , ending at 99 , Such as a crucible's class code is 01 , the bearing's class code is 02 . Therefore, the crucible in the raw materials warehouse can be coded 01.01.001, while the bearing6000 and bearing6005, the material code is 01.02.001 and 01.02.002. The way to code has some certain rules so that warehouse managers can be easy to remember and write. Either coding method, it should pay attention to the following aspects:

1) Material number should be simplistic. Try to use a combination of letters and numbers and it's simple and easy to operate.

2) The number musn't be repeated to ensure that a substance only has a number.

3) It is better that material coding have certain rules, in order to easily remember.

4) Material coding needs have reservation numbers, giving them to the new developed products afterwards.

Batch Management to Trace Material. Batch management refers to that the entire manufacturing process from raw materials to product must have a scientific management way by using the strict batch management, which runs through the whole manufacturing process of the product $^{[10]}$. In the enterprise's running, the majority of the materials require quality trace. Batch management can track the material and information flow.

All aluminum ingots will be given a number when they out from the furnace, the number is its batch. All silicon blocks and silicon ingots and the waste generated from an aluminum ingot in the production process also use the same number as aluminum ingot. Therefor, they are the same batch, and if there are some problems in one piece of silicon, we can directly use batch number to track and find the bad aluminum block. On the other hand, with the batch number, the company's material flow can translate to the information flow well in the system. Batch format can be set automatically in the ERP system, and it may also be set by the enterprises.

Optimize the Business Process. Failure in using ERP, the records of recipient and storage of materials are operated by a warehouse manager. It takes a lot of time picking and storing, stove workshop need to pick materials from cleaning workshop and raw materials warehouse. Any delay in the material preparation will lead to the stove workshop production can not be normal. It is necessary to optimize the process of materials' picking and storage.

The business process after optimizing is shown in Figure 2. the process compared with the past has the following advantages: 
1) The person who makes and checks the documents are not the same. In this case, each member is mutual monitoring and avoid abuse.

2) Increasing waste disposal sectors in the ERP system. Make a scarlet picking- list in the system, then send the waste materials to raw material warehouse for safekeeping. The waste wasn't put in storage and counted before, when checking the costs subsequently, the results will be different.

3) Raw material warehouse can achieve zero inventory. After using the way of pushing production, whether the materials are purchased or production waste, when they reach the raw material warehouse, all should be down to the washing plant to clean.

4) Each of the processes that prescribing, getting rid of head and tail, grinding has the process of picking and storing.Control the volume and the flow of material all the way, avoiding the condition that materials turn into dead materials in the case of piling long in the workshop.

5) Storage and requisition of materials will save a lot of time. If where goes wrong, managers can find a responsible person quickly.

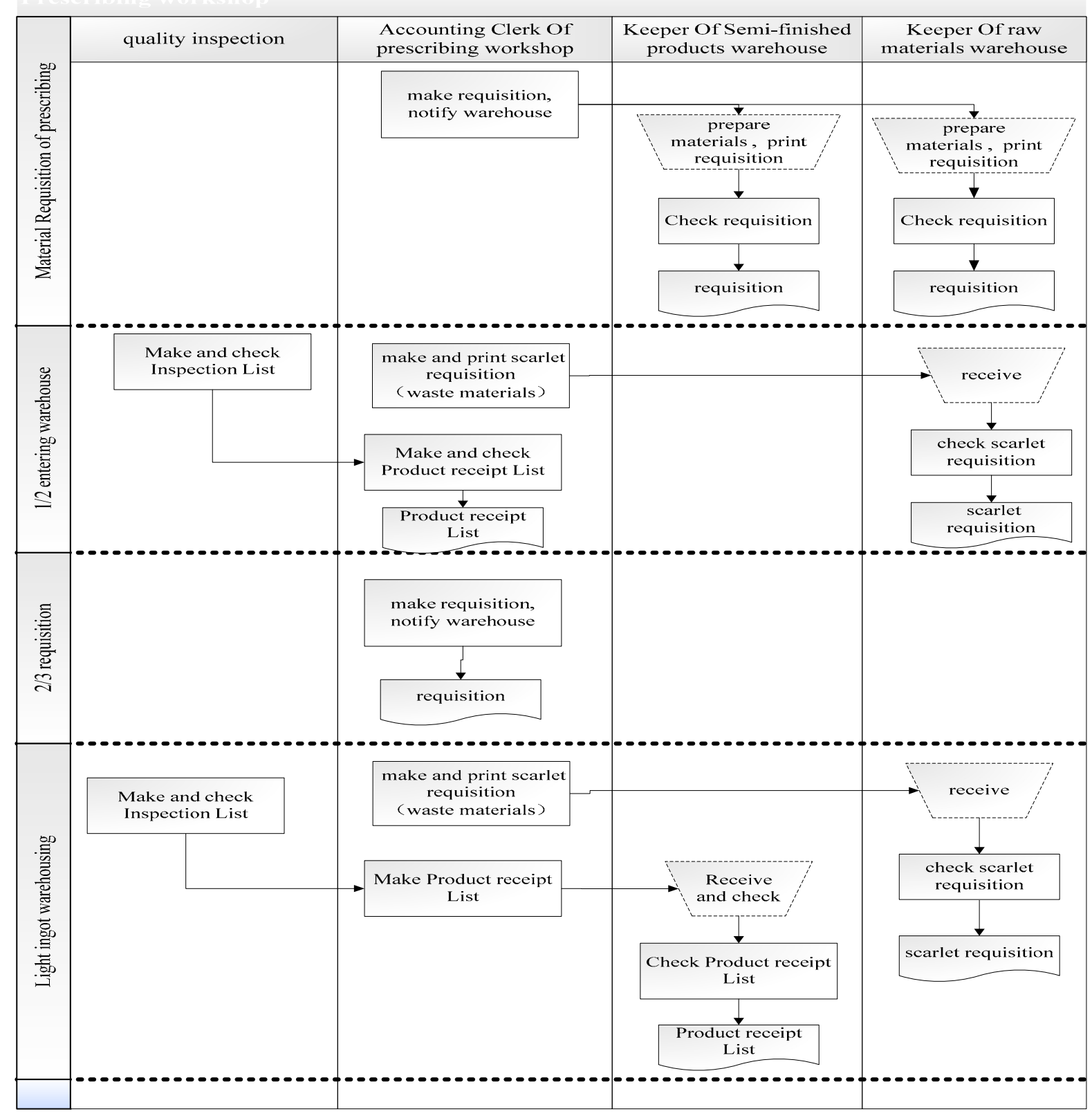

1-prescribing, 2-getting rid of head and tail ,3-grinding surface

fig. 2 the business process after optimizing 


\section{Conclusion}

The most important manifestation of ERP system's successful application in the enterprise is Optimizing business processes based on ERP environment. Continued optimization of business process can help companies combine business process with ERP system well, so that enterprises can have a scientific and standard management infrastructure. For domestic small and medium-sized enterprises that are under extensive management mode at long-tern and at the end of value of the supply chain, provides them the economic foundation to build its business transformation in a complex and volatile market environment and a strong technical support to the realize their long-term development goal.

For disordered material management in company $\mathrm{S}$, this paper proposed some solutions that the material coding, batch management, recipients and storage process optimizing closely related to inventory management theory and practical work experience, in the context of the ERP system. in practice, these programs have been applied very well and has successfully solved the problem of materials management chaotic.

In addition, according to the actual situation of Chinese current overall manufacturing sector, similar businesses are more and more, while the implementation of ERP systems are becoming more widely.Inventory management issues of company $\mathrm{S}$ have a good representation. Therefore, several methods proposed in the paper can be applied to more manufacturing enterprises.

\section{Acknowledgment}

The project has been supported by the Star Program of the State Ministry of Science and Technology(2014GA701032)and also sponsored by Zhejiang Provincial Natural Science Foundation (Y14G010002).

\section{References}

[1] Jiang Xiaofeng. A brief discussion on the significance of Enterprise Warehouse Management [J]. China Manganese, 2012,30 (4): 53-54.

[2] Zhou Taiping, Jiang Dongyan. A brief discussion on the warehouse management technology [J]. Technology and Enterprise, 2012, (9): 49.

[3] Dong Xueyan. A discussion on the inventory management [J]. Economist, 2009: (12).

[4] GanQuyan. Problems and Solutions in Supply Chain Inventory Management[J]. Guangxi Vocational and Technical College, 2012,2 (5): 68-70.

[5] Jiao Fangrong. Discussion on strengthening inventory management for enterprises[J]. Enterprise Herald, 2009, (04).

[6] MA Liping. Improving inventory management and corporate cash flow [J]. The financial sector, 2009, (11).

[7] Wang Li. Analysis of enterprise inventory management [J]. Heavy newspaper of Changchun City Party Committee, 2006, (12).

[8] Meijie. WangAn (S,S) Inventory Control Model with Return Flows[C]. 2011 International Conference on Business Management and Electronic Information, 2011.

[9] Zhou Wen-ong, Xu Ying, Shen Bing. Study on Spare Parts Inventory Control by Quantitative Analysis in the Environment of ERP System[C]. 2011 International Conference on Business Management and Electronic Information, 2011.

[10] Rosemary R.Fullerton, Cheryl S. McWatters, Chris Fawson . An examination of the relationships between JIT and financial performance[C] . Journal of Operations Management, 2003, (21): 383-404. 